\title{
A parametric study on the accuracy of bending in micro W-bending using Taguchi method
}

\author{
Xiaoyu Liu $^{\text {a, b }}$, Shiping Zhao ${ }^{\text {a,*, Yi Qin }}{ }^{\text {b,*, Jie Zhao }}{ }^{b}$, Wan-Adlan Wan-Nawang ${ }^{b}$ \\ ${ }^{a}$ School of Manufacturing Science and Engineering, Sichuan University, Chengdu, P.R. \\ China \\ ${ }^{b}$ Centre for Precision Manufacturing, Department of Design, Manufacture and \\ Engineering Management, University of Strathclyde, Glasgow, UK
}

\section{*Corresponding authors:}

Shiping Zhao, School of Manufacturing Science and Engineering, Sichuan University, Chengdu 610065, P.R. China.

E-mail address: spzhao@scu.edu.cn

Yi Qin, Centre for Precision Manufacturing, Department of Design, Manufacture and Engineering Management, University of Strathclyde, Glasgow G1 1XJ, UK.

E-mail address: qin.yi@strath.ac.uk 


\section{Abstract}

High dimensional accuracy of micro-bent parts, particularly the desired bent angle, is often required. In the study reported in this paper, a micro W-bending process was used for the study addressing this issue. Four main parameters affecting the bending accuracy of the micro W-bent parts were considered: foil thickness, grain size, foil orientation and punching frequency. Based on Taguchi $\mathrm{L}_{8}$ orthogonal array (OA), a micro-sheet-metal forming machine equipped with $\mathrm{W}$-shaped punch and die was used to conduct the micro $\mathrm{W}$-bending experiments. The experimental results were analyzed using signal-to-noise $(\mathrm{S} / \mathrm{N})$ ratio and the analysis of variance (ANOVA). It was identified that the extent of the effect by these parameters on the micro $\mathrm{W}$-bending process depends on springback behaviours. The foil thickness had highest influence on the springback amount of the bent parts. However, the negative springback was influenced mostly by the grain size, closely followed by the foil thickness. Furthermore, the optimum bending conditions for different types of the springback were obtained. Confirmation experiments were then performed not only to validate the improved bending accuracy but also to verify the extent of the contribution from each parameter to the amounts of the springbacks. Finally, mathematical models for both, positive springback and negative springback, were developed using the regression analysis. It was observed that the predicted values fit well with the experimental results, indicating the adequacy of the established models.

Keywords: Springback, Microforming, Taguchi method, Signal-to-noise ratio, ANOVA

\section{Introduction}

Micro-sheet-metal forming has been extensively adopted to fabricate various micro parts with low cost and high efficiency, such as electrical connectors, micro-springs, micro-mechanical parts, medical devices and implants [1-4]. With respect to the micro-bent parts, dimensional accuracy, especially bent angle, is of utmost importance. However, the springback, referring to the shape discrepancy between the designed configuration and the final bent parts after the release of bending load, often causes potential problems and further turn into a quality loss issue. It is thus crucial to control the 
amount of springback and to improve the bending accuracy, making the micro-bent parts to meet the requirements for dimensional tolerances. In general, the factors affecting the springback can be classified into the following four aspects: (1) bending method, such as free bending, three-point bending, U-bending and V-bending; (2) specimen dimensions and material properties, including sheet thickness, material type, yield strength, Young's modulus and some size-effect-related factors (grain size and grain orientation etc.); (3) tooling geometry, e.g. bending angle, radius, tool guide-surface, etc.; (4) process parameters, for example punch stroke, deformation rate, punching frequency holding time, lubrication and friction.

To date, many investigations have been undertaken using analytical methods, experimental studies, finite element method (FEM), and combinations of these methods, to study influences of various parameters on the springback. Chikalthankar et al. [5] reviewed several parameters affecting the springback such as punch angle, punch radius, punch height, material thickness and rolling direction. Reddy et al. [6] presented a review on the finite element analysis of springback and some compensation methods for springback. Chirita [7] explored the influences of blank holder force and lubrication between the specimen and punch surface in U-bending process. It was reported that the greater the friction, the smaller the springback. Tekıner [8] utilized four bending techniques and several dies in the V-bending tests to extensively investigate the springback of six types of materials. Three-point bending was adopted by Gau et al. [9] to examine the effects of grain size and brass thickness on the springback. They pointed out that the well-established concept of springback is not applicable when the material thickness is less than $350 \mu \mathrm{m}$. Tekaslan et al. [10] utilized a modular V-bending die to detect how punch holding time, sheet thickness and bending angle affected the springback of stainless steel. The springback was observed to decrease with increasing holding time and thickness and decreasing bending angle. Choudhury and Ghomi [11] carried out a comprehensive research on the influences of 11 parameters on the springback in V-bending dies. A significant improvement of springback was achieved by employing the analyses of S/N ratio and ANOVA. It was found that the punch holding time, material type and lubrication condition stayed in top three positions affecting the springback. Choi and Huh [12] investigated the influence of punch velocity on the springback in U-shaped 
bending via both experimental and numerical methods. It was demonstrated that when the punch velocity increased, the springback amount of DP780 increased whereas that of SPCC decreased.

Apart from the springback, in some circumstances, the negative springback was observed as well. Bakhshi-Jooybari et al. [13] examined how punch radius, material thickness and anisotropy influenced the springback and negative springback in V-die and U-die bending processes by FEM simulations and experiments. The negative springback only appeared in V-bending. Moreover, the angle between the rolling direction and the bending axis was discovered to affect both the springback and negative springback. Various mathematical models based on the statistical analysis were additionally developed to predict the springback [14]. Thipprakmas and Rojananan [15] employed the FEM technique to study the springback and negative springback behaviours in V-shaped bending process. Thipprakmas and Phanitwong [16] explored the degree of influence of three parameters, e.g. sheet thickness, bending angle and punch radius, on the springback and negative springback in $\mathrm{V}$-shaped punch and die. It is revealed that the material thickness is the dominant factor influencing the springback, whereas the bending angle has the highest contribution to the negative springback. Hakan et al. [17] explored how punch tip radius, holding time and the heat treatment condition (non-heat-treated, normalized and tempered) affected the negative springback in a $90^{\circ} \mathrm{V}$-bending die. It was addressed that with decreasing punch radius and holding time, the amount of negative springback increased. Moreover, it also increased in the normalized specimens, whereas decreased in the tempered ones. Chen [18] considered the influences of punch speed, punch radius and grain size of pure iron sheet on the springback and negative springback in V-shaped bending tests and drawn a conclusion that the amount of negative springback could be reduced by the decreased punch speed when the grain size was large.

From the available literatures, it is indicated that the bending accuracy of micro parts is not only influenced by the springback; in fact, the negative springback also poses significant impact on the bending accuracy. However, most of the investigations conducted so far have dealt only with conventional bending processes, such as three-point bending [9, 19, 20], free-bending [21], U-bending [7, 13] and V-bending [8, 11, 18], rather than the complicated micro-bending process with the multi-curvature shape presented in 
this research. Furthermore, in terms of negative springback, most studies were carried out in the macro-scaled bending process with material thickness larger than $100 \mu \mathrm{m}$. In addition, some material properties such as grain size and grain orientation, were merely quantitatively described instead of statistically analyzed. Based on the considerations presented above, therefore, $\mathrm{S} / \mathrm{N}$ ratio and ANOVA were adopted to investigate how various parameters, especially the material properties, affected the bending accuracy in a micro W-bending process. Afterwards, the significant contribution of each parameter and the optimum bending conditions for the springback and negative springback were analyzed respectively. The results were further verified by confirmation tests. Mathematical models were established to describe the quantitative relationship between the parameters and the springback and negative springback.

\section{Experimental procedure}

\subsection{Micro W-bending process}

A novel micro $\mathrm{W}$-bending process was proposed to fabricate the $\mathrm{W}$-shaped micro parts. It is a kind of micro clips used to mount the fibre Bragg grating on the tendon of the object to measure the change in strain or temperature, which have been widely employed in optical communication, sensing systems and electronics products. The micro W-bending experiments were carried out on the micro-sheet forming machine equipped with the $\mathrm{W}$-shaped punch and die, as shown in Fig. 1a. Using a linear-motor-driven mechanism, the maximum force provided by the machine is $5.3 \mathrm{kN}$. In addition, a load cell with a measurement resolution of $0.1 \mathrm{~N}$ and a positional encoder providing the $0.1 \mu \mathrm{m}$ vertical-position-resolution are integrated into the machine [22]. As illustrated in the schematic drawings of the W-shaped punch and die (Fig. 1b), the ideal bent angle of micro parts is 80 degrees. Considering the forming feasibility, the tip radii on the $\mathrm{W}$-shaped punch and die are marginally different. The W-groove on the die (Rd) has two different radii: $0.35 \mathrm{~mm}$ for the middle radius and $0.15 \mathrm{~mm}$ for the radii on both sides, whereas the tip radii on the punch $(\mathrm{Rp})$ are 0.4 and $0.1 \mathrm{~mm}$, respectively. 


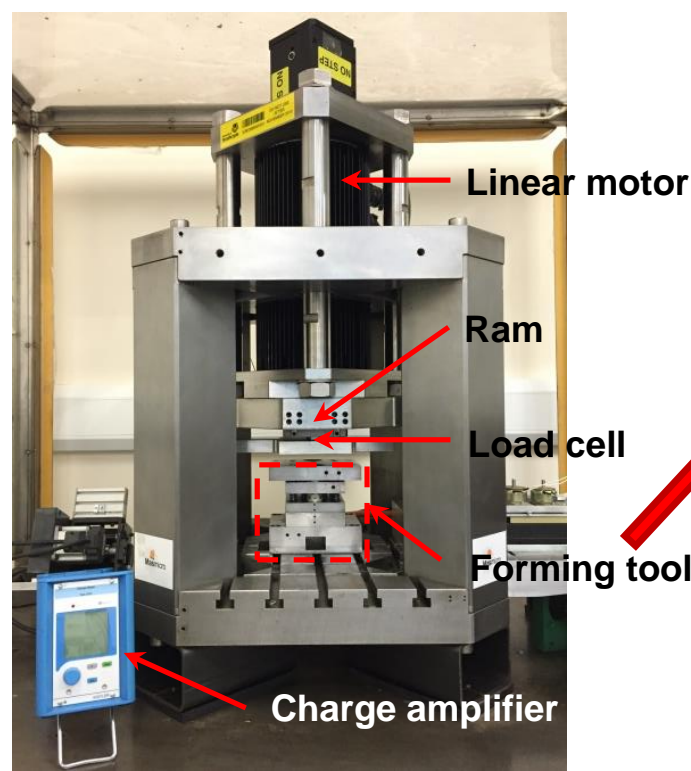

(a)

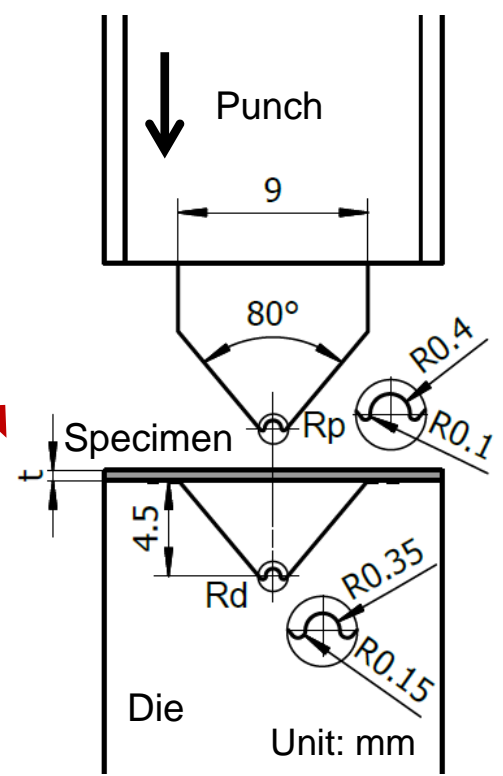

(b)

Fig. 1. Schematic illustrations of (a) micro-sheet forming machine and (b) W-shaped punch and die.

In this study, CuZn37 brass foils were chosen as the experimental material since it has good mechanical properties and excellent formingability. The bending specimens used in the experiments are $16 \mathrm{~mm}$ long and $12 \mathrm{~mm}$ wide. After micro W-bending experiments, a vision measuring microscope, Mitutoyo Quick Scope, was applied to measure the final bent angle. Fig. 2 illustrates how the bent angle of a W-shaped micro part was measured under Mitutoyo Quick Scope.

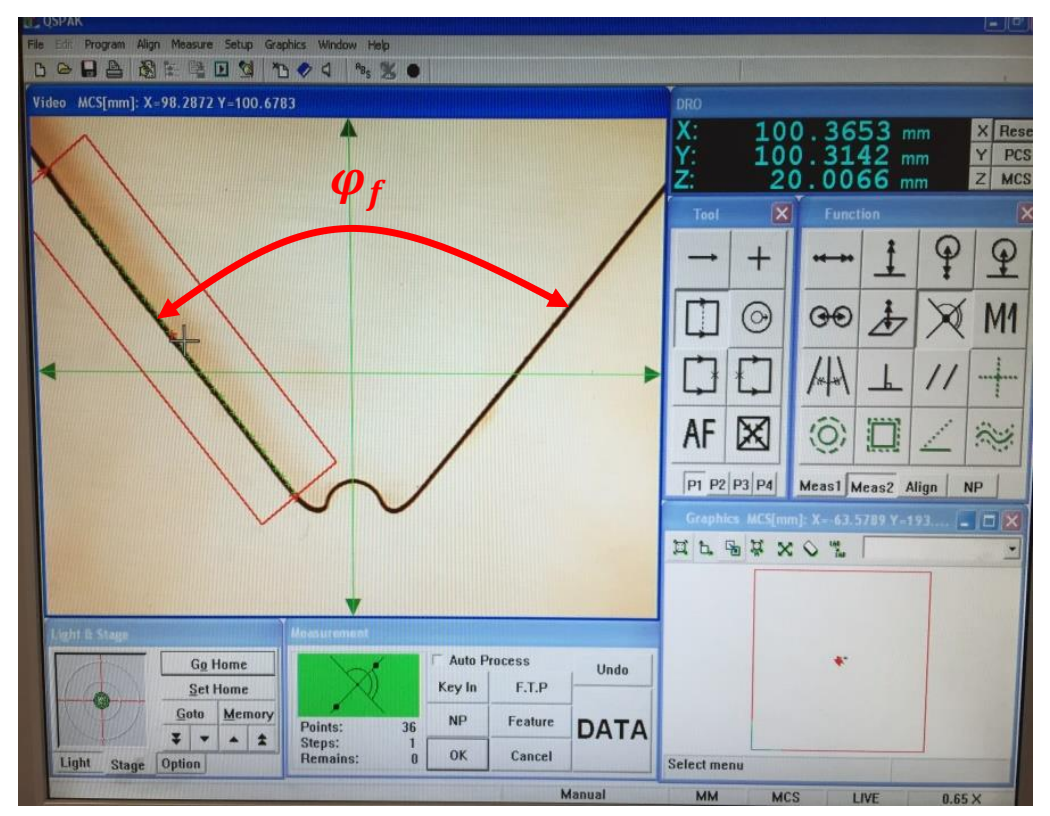

Fig. 2. The bent angle of a W-shape micro part measured under Mitutoyo Quick Scope. 
As shown in Fig.2, the final bent angle is defined as the angle between two edges after the bending load is released. These two edges were fitted and analyzed using the equipped QSPAK software and then the bent angle was measured with the measurement resolution of 1". Subsequently, the springback angle could be calculated by Eq. (1):

$$
\varphi=\varphi_{f}-\varphi_{0}
$$

where $\varphi$ stands for the springback angle, $\varphi_{f}$ denotes the final bent angle, and $\varphi_{0}$ is the ideal bent angle which is $80^{\circ}$. Usually, the final bent angle slightly opens producing a positive springback, whereas the negative springback occurs when the bent part presents a smaller bent angle after the load is released [23]. In the micro W-bending process, both the springback and negative springback were observed.

In order to explore how these parameters affect the springback and negative springback, foil thickness (A), foil orientation (B), grain size (C) and punching frequency (D) are considered to be potentially important factors influencing the bending accuracy of the W-shaped micro parts. Table 1 depicts the abovementioned parameters with two levels investigated in the micro W-bending experiments.

Table 1 Four parameters with two levels in micro W-bending experiments.

\begin{tabular}{|c|c|c|c|c|c|}
\hline \multirow[t]{2}{*}{ Symbol } & \multirow[t]{2}{*}{ Parameters } & \multicolumn{2}{|c|}{ Springback } & \multicolumn{2}{|c|}{ Negative springback } \\
\hline & & Level 1 & Level 2 & Level 1 & Level 2 \\
\hline $\mathrm{A}$ & Foil thickness, $t(\mu \mathrm{m})$ & 25 & 50 & 75 & 100 \\
\hline B & Foil orientation, $\theta\left(^{\circ}\right)$ & 0 & 90 & 0 & 90 \\
\hline $\mathrm{C}$ & Grain size, $d(\mu \mathrm{m})$ & $33(46.3)$ & $41.2(75)$ & $56.6(62.8)$ & $98.5(105.7)$ \\
\hline $\mathrm{D}$ & $\begin{array}{l}\text { Punching frequency, } f \\
(\mathrm{~Hz})\end{array}$ & 0.20 & 0.25 & 0.20 & 0.25 \\
\hline
\end{tabular}

As shown in the table, for springback, the data 33 and 41.2 are the grain sizes of $25 \mu \mathrm{m}$ thick specimens under level 1 and level 2 respectively. The values in brackets (46.3 and 75) represent the grain sizes of $50 \mu \mathrm{m}$ thick specimens under the corresponding levels. Similarly, for negative springback, data 62.8 and 105.7 are the grain sizes of $100 \mu \mathrm{m}$ thick specimens under level 1 and level 2.

It is found in Table 1 that apart from the process parameter (punching frequency), this study also examined several material-related parameters, e.g. foil thickness, foil orientation and grain size, which start to be important factors affecting the bending 
accuracy of micro parts after size effect arises in the micro-scale forming. However, these material properties, especially for the grain size, have not been investigated in previous parametric studies, and their quantitative influences on the bending accuracy are still unknown.

The levels of factors were selected by conducting the preliminary pilot experiments. The lower level of the foil orientation ( 0 degree) means that the rolling direction of the specimen is parallel to the bending axis. Accordingly, the higher level (90 degrees) means that they are perpendicular to each other. With a view to obtaining various grain sizes for the brass foils with different thicknesses, the annealing treatments were carried out under $550^{\circ} \mathrm{C}$ with one-hour holding time (level 1), and $650^{\circ} \mathrm{C}$ with three-hour holding time (level 2), respectively. To avoid the influence of oxidation layer on the foil thickness, the annealing treatments were performed in the $90 \% \mathrm{~N} 2+10 \% \mathrm{H} 2$ protection condition before furnace cooling to room temperature. It was found that the color of the foil surface was not changed and the foil thickness still remained the same as the nominal value. As a consequence, the nominal values of the foil thicknesses are presented in Table 1.

After the treatment, the microstructures of the material were observed by a metallographic microscope and then ASTM E112 standard was adopted to measure the grain size. The microstructures of specimens along the foil plane are presented in Fig. 3.
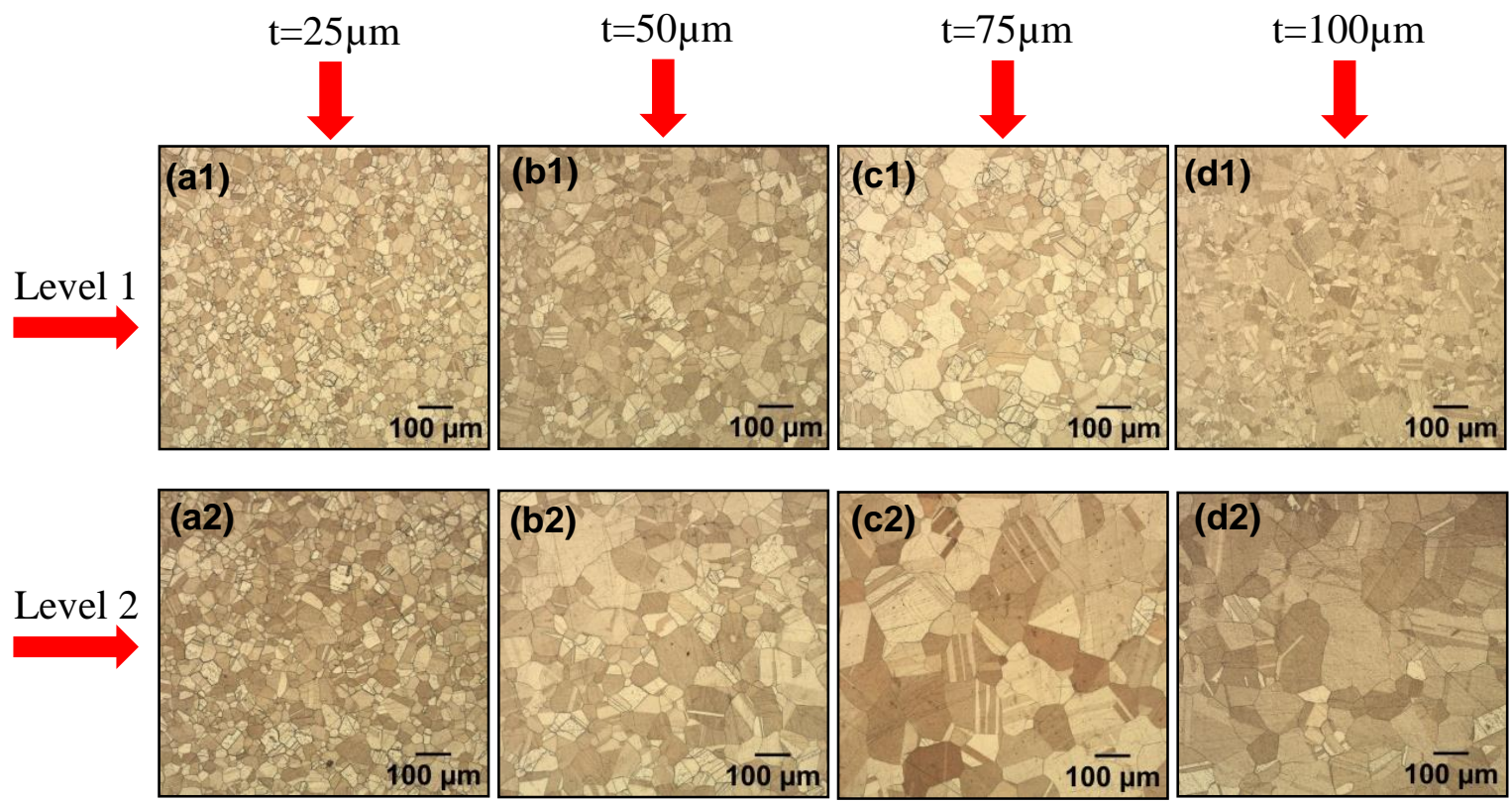

Fig.3. Microstructures of annealed brass foils along the foil plane: (a1) $d=33 \mu \mathrm{m}$, (a2) $d$ $=41.2 \mu \mathrm{m},(\mathrm{b} 1) \mathrm{d}=46.3 \mu \mathrm{m},(\mathrm{b} 2) \mathrm{d}=75 \mu \mathrm{m},(\mathrm{c} 1) \mathrm{d}=56.6 \mu \mathrm{m}$, (c2) $\mathrm{d}=98.5 \mu \mathrm{m}$, (d1) $\mathrm{d}=$ 
$62.8 \mu \mathrm{m},(\mathrm{d} 2) \mathrm{d}=105.7 \mu \mathrm{m}$.

Moreover, the punching frequency was chosen to describe how fast the punch moves. When the punching frequency decreases, it means the punch velocity decreases. In addition, no lubricant was used between the surfaces of the specimen and the W-shaped punch and die in all the bending experiments.

\subsection{Design of experiments based on Taguchi method}

The Taguchi method, a statistical and efficient technique for product design and process optimization [24-27], has been widely used to achieve the off-line quality control $[28,29]$. As the most reliable step in the Taguchi approach, the parameter design emphasizes on obtaining the optimum combination of parameters to improve a quality characteristic with low variability, enabling the achievement of the robustness (insensitive to the effects of noises or the uncontrollable factors) [30].

For the design of experiments, an $\mathrm{L}_{8}$ standard OA was adopted in this study, as shown in Table 2. In comparison with the full factorial design method, OA is efficient and cost-saving due to the small number of experimental runs.

Table 2 An $\mathrm{L}_{8}$ standard orthogonal array for micro W-bending experiments.

\begin{tabular}{lllll}
\hline \multirow{2}{*}{$\begin{array}{l}\text { Experiment } \\
\text { No. }\end{array}$} & \multicolumn{3}{l}{ Factor } \\
\cline { 2 - 5 } & A & B & C & D \\
\hline 1 & 1 & 1 & 1 & 1 \\
2 & 1 & 1 & 2 & 2 \\
3 & 1 & 2 & 1 & 2 \\
4 & 1 & 2 & 2 & 1 \\
5 & 2 & 1 & 1 & 2 \\
6 & 2 & 1 & 2 & 1 \\
7 & 2 & 2 & 1 & 1 \\
8 & 2 & 2 & 2 & 2 \\
\hline
\end{tabular}

Taguchi introduced loss function for indicating the discrepancies between the experimental results and desired values [23], as depicted in Eq. (1). The springback and negative springback, subsequently, are converted into $\mathrm{S} / \mathrm{N}$ ratios to measure the performance characteristics of the W-shaped micro-bent parts. Typically, three kinds of $\mathrm{S} / \mathrm{N}$ ratios are applied to quantify the quality, such as the nominal-the-better, the 
smaller-the-better and the larger-the-better [31]. Here, with a view to minimizing the springback and negative springback amounts, the smaller-the-better type is employed for the calculation of $\mathrm{S} / \mathrm{N}$ ratios using Eq. (2):

$$
\mathrm{S} / N=-10 \log \left[\frac{1}{n}\left(y_{1}^{2}+y_{2}^{2}+\cdots+y_{n}^{2}\right)\right]
$$

where $y_{1}, y_{2, \ldots} y_{n}$ represent the measured bent angles in the bending process, and each bending condition is repeated $\mathrm{n}$ times. Afterwards, the main influences of $\mathrm{S} / \mathrm{N}$ ratios at every parameter level were analyzed and plotted. ANOVA was then utilized to assess whether the parameters have statistically-significant impacts on the springback and negative springback, along with their corresponding contributions to the quality characteristic. On the basis of analyzing the main influences of S/N ratios and ANOVA, the optimum combination of parameter levels can be obtained. Finally, confirmation experiments were performed not only to validate the combination of optimum parameters derived from the proposed design of micro W-bending experiments, but also to verify the extent of the contribution from the parameters on the springback and negative springback.

\section{Results, analysis and discussion}

Fig. 4 exhibits the W-shaped micro-bent parts. The experimental results of the springback and negative springback are listed in Tables 3 and 4, together with their corresponding S/N ratios computed using Eq. (2). According to the $\mathrm{L}_{8}$ standard OA, experiments numbered 18 generated springback, whereas experiments numbered with 9-16 yielded negative springback.

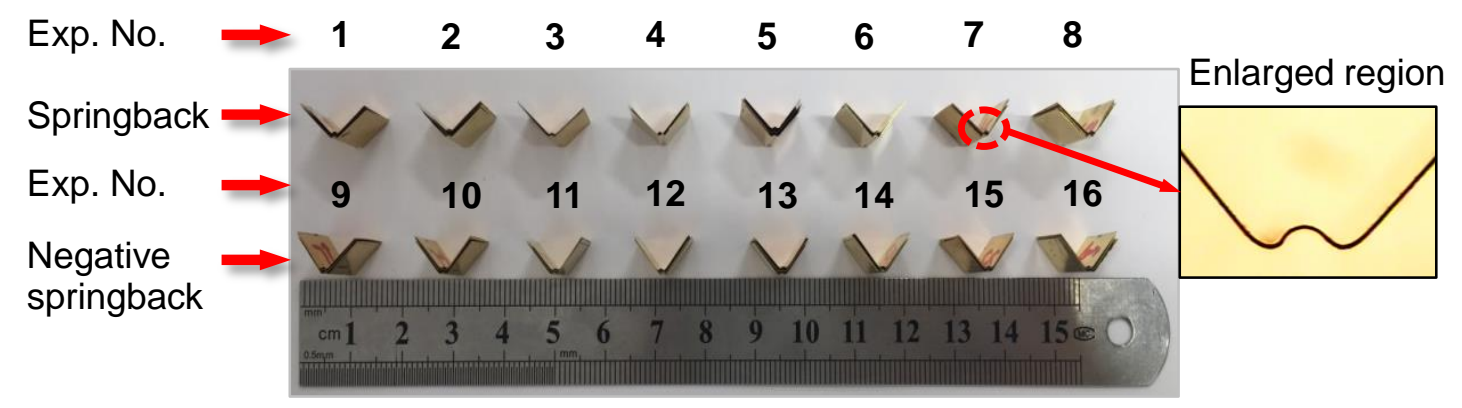

Fig. 4. W-shaped micro-bent parts. 
In Tables 3 and 4 , for each of the eight $\mathrm{L}_{8} \mathrm{OA}$ settings, three parts were produced and named as Part 1, Part 2 and Part 3, respectively. For a single part, the measurement was repeated three times and $\overline{\varphi_{S B n}}$ is used to stand for the average measured angle for the springback and $\overline{\varphi_{N S B n}}$ is used for the negative springback angle. The standard deviations (SD) of the measured angles on the same part due to measurement repeatability are also presented in Tables 3 and 4. Furthermore, the bent angles for Part 1, Part 2 and Part 3 were averaged again and thus this value $\left(\overline{\varphi_{S B}}\right.$ for the averaged springback angle and $\overline{\varphi_{N S B}}$ for the averaged negative springback angle) is considered as the final bent angle for these three different parts produced under the same W-bending condition. Bending SD is also addressed to describe the standard deviation of the measured angle on different parts due to repeatability of the $\mathrm{W}$-bending process.

Table 3 Springback angles and corresponding $\mathrm{S} / \mathrm{N}$ ratios.

\begin{tabular}{|c|c|c|c|c|c|c|c|c|c|}
\hline \multirow{2}{*}{$\begin{array}{l}\text { Exp. } \\
\text { No. }\end{array}$} & \multicolumn{2}{|l|}{ Part 1} & \multicolumn{2}{|l|}{ Part 2} & \multicolumn{2}{|l|}{ Part 3} & \multirow{2}{*}{$\begin{array}{l}\overline{\varphi_{S B}} \\
\left(^{\circ}\right) \\
\end{array}$} & \multirow{2}{*}{$\begin{array}{l}\text { Bending } \\
\mathrm{SD}\left(^{\circ}\right)\end{array}$} & \multirow{2}{*}{$\begin{array}{l}\mathrm{S} / \mathrm{N} \text { ratio } \\
(\mathrm{dB})\end{array}$} \\
\hline & $\overline{\varphi_{S B 1}}\left(^{\circ}\right)$ & $\mathrm{SD} 1\left(^{\circ}\right)$ & $\overline{\varphi_{S B 2}}\left(^{\circ}\right)$ & $\mathrm{SD} 2\left(^{\circ}\right)$ & $\overline{\varphi_{S B 3}}\left({ }^{\circ}\right)$ & SD3 $\left(^{\circ}\right)$ & & & \\
\hline 1 & 15.084 & 0.086 & 14.371 & 0.099 & 13.565 & 0.150 & 14.340 & 0.760 & -23.139 \\
\hline 2 & 14.585 & 0.036 & 16.253 & 0.056 & 15.287 & 0.168 & 15.375 & 0.837 & -23.745 \\
\hline 3 & 15.423 & 0.270 & 17.978 & 0.099 & 16.838 & 0.093 & 16.746 & 1.280 & -24.495 \\
\hline 4 & 7.343 & 0.041 & 7.309 & 0.094 & 8.870 & 0.006 & 7.841 & 0.891 & -17.924 \\
\hline 5 & 5.093 & 0.107 & 6.834 & 0.208 & 5.543 & 0.024 & 5.824 & 0.904 & -15.373 \\
\hline 6 & 1.612 & 0.036 & 2.974 & 0.057 & 1.588 & 0.047 & 2.058 & 0.793 & -6.678 \\
\hline 7 & 1.291 & 0.097 & 1.960 & 0.056 & 0.671 & 0.060 & 1.307 & 0.645 & -2.979 \\
\hline 8 & 0.052 & 0.210 & 1.273 & 0.151 & 3.577 & 0.047 & 1.634 & 1.790 & -6.817 \\
\hline
\end{tabular}

Table 4 Negative springback angles and corresponding S/N ratios.

\begin{tabular}{|c|c|c|c|c|c|c|c|c|c|}
\hline \multirow{2}{*}{$\begin{array}{l}\text { Exp. } \\
\text { No. }\end{array}$} & \multicolumn{2}{|l|}{ Part 1} & \multicolumn{2}{|l|}{ Part 2} & \multicolumn{2}{|l|}{ Part 3} & \multirow{2}{*}{$\begin{array}{l}\overline{\varphi_{N S B}} \\
\left(^{\circ}\right) \\
\end{array}$} & \multirow{2}{*}{$\begin{array}{l}\text { Bending } \\
\mathrm{SD}\left({ }^{\circ}\right)\end{array}$} & \multirow{2}{*}{$\begin{array}{l}\mathrm{S} / \mathrm{N} \text { ratio } \\
(\mathrm{dB})\end{array}$} \\
\hline & $\overline{\varphi_{N S B 1}}\left({ }^{\circ}\right)$ & SD1 $\left({ }^{\circ}\right)$ & $\overline{\varphi_{N S B 2}}\left({ }^{\circ}\right)$ & SD2 $\left(^{\circ}\right)$ & $\overline{\varphi_{N S B 3}}\left({ }^{\circ}\right)$ & SD3 $\left(^{\circ}\right)$ & & & \\
\hline 9 & -1.487 & 0.025 & -2.312 & 0.497 & -2.175 & 0.118 & -1.991 & 0.442 & -6.123 \\
\hline 10 & -1.590 & 0.169 & -3.018 & 0.359 & -2.531 & 0.021 & -2.380 & 0.726 & -7.792 \\
\hline 11 & -0.947 & 0.119 & -1.288 & 0.067 & -2.223 & 0.042 & -1.486 & 0.661 & -3.977 \\
\hline 12 & -4.311 & 0.015 & -5.549 & 0.062 & -5.022 & 0.087 & -4.961 & 0.622 & -13.956 \\
\hline 13 & -3.854 & 0.211 & -0.403 & & -1.810 & & -2.022 & & -7.852 \\
\hline 14 & -4.300 & 0.128 & -5.290 & 0.026 & -4.447 & 0.214 & -4.679 & 0.534 & -13.440 \\
\hline 15 & -4.004 & 0.125 & -4.189 & 0.105 & -2.767 & 0.121 & -3.653 & 0.773 & -11.382 \\
\hline 16 & -4.582 & 0.041 & -4.364 & 0.081 & -4.479 & 0.029 & -4.475 & 0.109 & -13.018 \\
\hline
\end{tabular}

Then, the $\mathrm{S} / \mathrm{N}$ response tables were summarized to indicate the influence of each 
factor on the springback and negative springback by calculating the means of the signal-to-noise ratios at each level (see Tables 5 and 6, respectively).

Table 5 Response table of average $\mathrm{S} / \mathrm{N}$ ratio for springback.

\begin{tabular}{llccc}
\hline Level & $\mathrm{A}: t(\mu \mathrm{m})$ & $\mathrm{B}: \theta\left(^{\circ}\right)$ & $\mathrm{C}: d(\mu \mathrm{m})$ & $\mathrm{D}: f(\mathrm{~Hz})$ \\
\hline 1 & -22.326 & -17.234 & -16.497 & -12.680 \\
2 & -7.962 & -13.054 & -13.791 & -17.608 \\
Max-Min & 14.364 & 4.180 & 2.706 & 4.927 \\
Rank & 1 & 3 & 4 & 2 \\
\hline
\end{tabular}

Table 6 Response table of average S/N ratio for negative springback.

\begin{tabular}{lllll}
\hline Level & $\mathrm{A}: t(\mu \mathrm{m})$ & $\mathrm{B}: \theta\left(^{\circ}\right)$ & $\mathrm{C}: d(\mu \mathrm{m})$ & $\mathrm{D}: f(\mathrm{~Hz})$ \\
\hline 1 & -7.962 & -8.802 & -7.334 & -11.225 \\
2 & -11.423 & -10.583 & -12.052 & -8.160 \\
Max-Min & 3.460 & 1.781 & 4.718 & 3.066 \\
Rank & 2 & 4 & 1 & 3 \\
\hline
\end{tabular}

Subsequently, the main influence plots of signal-to-noise ratios of the four parameters at every level for the springback and negative springback are more clearly presented in Figs. 5 and 6. According to the Taguchi technique, a bigger $\mathrm{S} / \mathrm{N}$ ratio represents a better performance, implying a smaller amount of the springback or negative springback in this study.

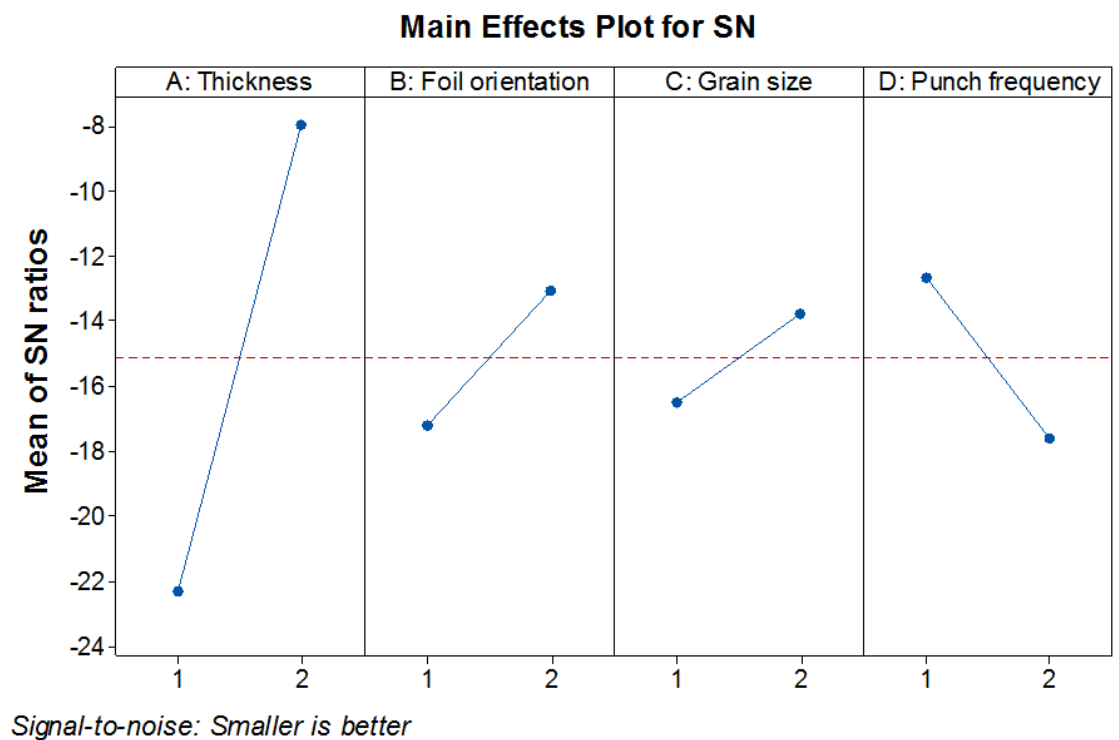

Fig. 5. Influence of parameters at every level on springback.

As seen in Fig. 5, when the foil thickness increased, the $\mathrm{S} / \mathrm{N}$ ratio sharply increased, 
denoting the amount of springback significantly decreased. As the angle between the rolling direction and the bending axis increased from $0^{\circ}$ to $90^{\circ}$, the springback experienced a gradual decrease. In addition, with increasing grain size, a smooth rise of $\mathrm{S} / \mathrm{N}$ ratio was found, indicating a slightly decreased amount of springback, which was attributed to the increased proportion of the surface grains to the interior ones yielding a decrease of the material strength. However, when the punching frequency increased, the springback presented a striking increase. These obtained results are in accordance with those reported in the previous investigations [18, 19, 32]. In contrast to the springback, however, the parameters exhibited opposite tendencies of the influences on the negative springback (see Fig. 6). Thus far, these results corresponding to the negative springback were rarely addressed, especially in a new micro W-bending process.

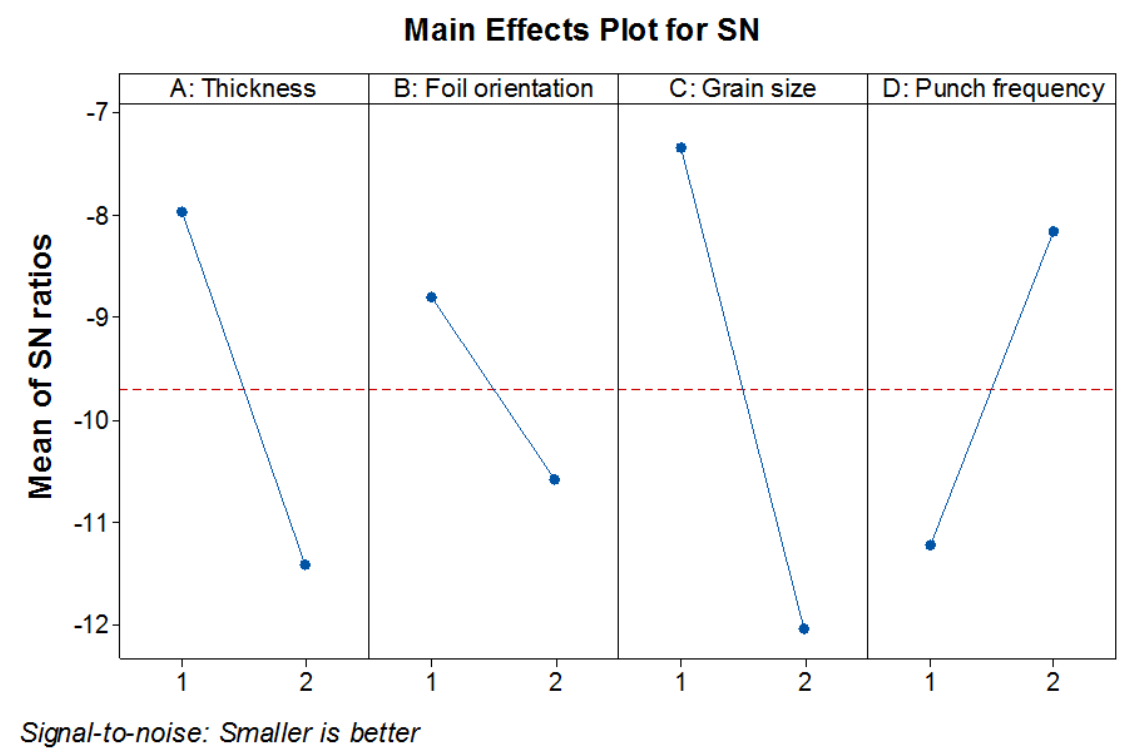

Fig. 6. Influence of parameters at every level on negative springback.

ANOVA was also performed by utilizing the $\mathrm{S} / \mathrm{N}$ ratios to assess the significance and the degree of importance of the factors on the output responses. Tables 7 and 8 list ANOVA results with $95 \%$ confidence for the springback and negative springback, respectively, computed using Minitab 17.

Table 7 ANOVA for springback.

\begin{tabular}{llllrll}
\hline Source & $d f$ & Sum of squares & Mean square & \multicolumn{1}{l}{$F$} & $P$ & Remarks \\
\hline A & 1 & 412.640 & 412.640 & 109.31 & 0.002 & Significant \\
B & 1 & 34.940 & 34.940 & 9.26 & 0.056 & Non-significant \\
C & 1 & 14.640 & 14.640 & 3.88 & 0.144 & Non-significant
\end{tabular}




\begin{tabular}{lrcrrrr} 
D & 1 & 48.558 & 48.558 & 12.86 & 0.037 & Significant \\
Error & 3 & 11.32 & 3.775 & & & \\
Total & 7 & 522.10 & & & & \\
\hline
\end{tabular}

Table 8 ANOVA for negative springback.

\begin{tabular}{llccrll}
\hline Source & $d f$ & Sum of squares & Mean square & \multicolumn{1}{l}{$F$} & $P$ & Remarks \\
\hline A & 1 & 23.949 & 23.949 & 14.60 & 0.032 & Significant \\
B & 1 & 6.347 & 6.347 & 3.87 & 0.144 & Non-significant \\
C & 1 & 44.519 & 44.519 & 27.13 & 0.014 & Significant \\
D & 1 & 18.797 & 18.797 & 11.46 & 0.043 & Significant \\
Error & 3 & 4.922 & 1.641 & & & \\
Total & 7 & 98.534 & & & & \\
\hline
\end{tabular}

In the table, $d f$ is the degree of freedom of each parameter. $F$ test was performed to assess whether the detected effect is reliable. Moreover, $P$ value is an indicator to represent whether a factor is significant or not. If it is less than 0.05 , then the factor is considered to play a significant role on the quality characteristics. According to the obtained results, the foil thickness and punching frequency significantly affected the springback, whereas the foil orientation was only non-significant factor presenting little effect on the negative springback.

Furthermore, it was identified that the extent of the contribution from each of these parameters on the micro W-bending process depends on the type of the springback. To approach a clear illustration, the percentage of the contributions of the parameters to different springback behaviours, derived from the sum of squares, are compared in Fig. 7. Specifically, in the case of springback, it was observed that the foil thickness was the dominant factor with a contribution of $79.03 \%$. As the second contributor, the punching frequency also contributed $9.30 \%$. However, the foil orientation $(6.69 \%)$ and the grain size $(2.80 \%)$ exhibited slight effects on the springback amount. Referring to the negative springback, the grain size had the highest contribution (45.18\%), closely followed by the foil thickness $(24.31 \%)$. The punching frequency also presented a significant contribution (19.08\%). The foil orientation, however, ranked the last, with only $6.44 \%$ contribution. 


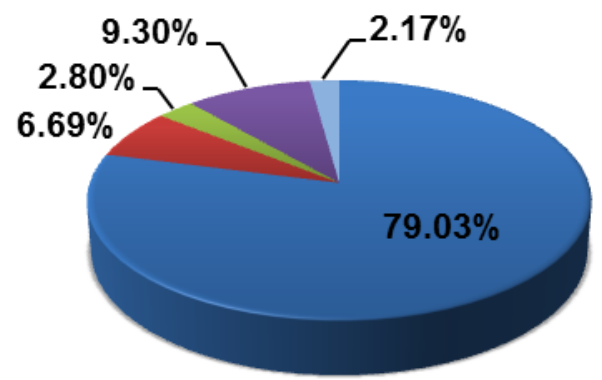

(a)

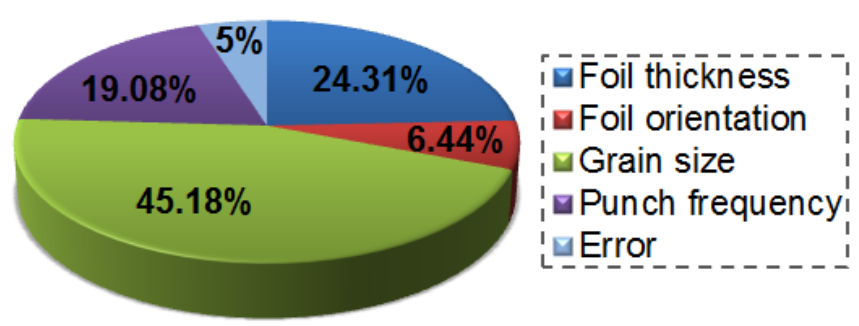

(b)

Fig. 7. Percentage of the contribution from the parameters on the springback (a) and negative springback (b).

From the analyses of the main influences of $\mathrm{S} / \mathrm{N}$ ratios and ANOVA, the optimum combination of parameters for the springback is A2B2C2D1 i.e. foil thickness is $50 \mu \mathrm{m}$, foil orientation is $90^{\circ}$, grain size is $75 \mu \mathrm{m}$ (level 2: annealed under $650^{\circ} \mathrm{C}$ with three-hour holding time), punching frequency is $0.2 \mathrm{~Hz}$. Similarly, the optimum combination of parameters to obtain a better performance for the negative springback is A1B1C1D2 i.e. foil thickness is $75 \mu \mathrm{m}$, foil orientation is $0^{\circ}$, grain size is $56.6 \mu \mathrm{m}$ (level 1: annealed under $550^{\circ} \mathrm{C}$ with one-hour holding time), punching frequency is $0.25 \mathrm{~Hz}$.

\subsection{Confirmation tests of the optimum bending conditions}

To predict the quality characteristic and verify its improvement at the optimum bending conditions, confirmation experiments were conducted by calculating the predicted S/N ratios using Eq. (3) [24]:

$$
\hat{\eta}=\eta_{m}+\sum_{i=1}^{o}\left(\bar{\eta}_{i}-\eta_{m}\right)
$$

where $\eta_{m}$ stands for the overall average $\mathrm{S} / \mathrm{N}$ ratio, $\bar{\eta}_{i}$ represents the average $\mathrm{S} / \mathrm{N}$ ratio at every optimum level, and $o$ denotes the number of parameters influencing quality characteristics. As shown in Tables 9 and 10 (for the springback and negative springback respectively), the predicted values were found to be close to the experimental results at the optimum levels of the parameters. Furthermore, obvious improvements of the quality characteristic for the springback (decreased from $2.509^{\circ}$ to $1.038^{\circ}$ ) and the negative springback (decreased from $-3.568^{\circ}$ to $-0.179^{\circ}$ ) were observed when the $\mathrm{S} / \mathrm{N}$ ratios increased by $8.349 \mathrm{~dB}$ and $12.283 \mathrm{~dB}$ from the initial parameter level to the optimum level. 
Accordingly, the confirmation tests have verified the analyses of $\mathrm{S} / \mathrm{N}$ ratios and ANOVA to select each optimum level of bending parameters in this study.

Table 9 Results of confirmation experiments of optimum bending parameters for springback.

\begin{tabular}{llll}
\hline & $\begin{array}{l}\text { Initial bending } \\
\text { parameters }\end{array}$ & \multicolumn{2}{l}{ Optimal bending parameters } \\
\cline { 3 - 4 } & A2B1C1D1 & A2B2C2D1 & A2Beriment \\
\hline Level & 2.509 & & 1.038 \\
Springback $\left(^{\circ}\right)$ & -8.716 & -2.056 & -0.367 \\
S/N ratio $(\mathrm{dB})$ & & \\
Improvement of S/N ratio $=8.349 \mathrm{~dB}$ & & \\
\hline
\end{tabular}

Table 10 Results of confirmation experiments of optimum bending parameters for negative springback.

\begin{tabular}{llll}
\hline & $\begin{array}{l}\text { Initial bending } \\
\text { parameters }\end{array}$ & \multicolumn{2}{l}{ Optimal bending parameters } \\
\cline { 3 - 4 } & A2B1C1D1 & Arediction & Experiment \\
\hline Level & -3.568 & & A1B1C1D2 \\
Negative springback $\left(^{\circ}\right)$ & -11.055 & -3.180 & -0.179 \\
$\mathrm{~S} / \mathrm{N}$ ratio $(\mathrm{dB})$ & & 1.228 \\
Improvement of $\mathrm{S} / \mathrm{N}$ ratio $=12.283 \mathrm{~dB}$ & & \\
\hline
\end{tabular}

\subsection{Confirmation tests of the percentage contribution of parameters}

To validate the contribution of the parameters on the bending accuracy, experiments were additionally conducted by increasing or decreasing the levels for each parameter [33]. The arrangements of experiments are listed in Tables 11 and 12, in association with their corresponding results illustrated in Figs. 8 and 9 respectively. Each case was repeated three times to calculate the average value.

Table 11 Experimental arrangements of contribution confirmation tests for springback.

\begin{tabular}{llllll}
\hline Bending parameters & \multicolumn{3}{l}{ Case } & & \\
\cline { 2 - 6 } & $(1)($ Ref. $)$ & $(2)$ & $(3)$ & $(4)$ & $(5)$ \\
\hline A: Foil thickness, $t(\mu \mathrm{m})$ & 50 & 25 & 50 & 50 & 50 \\
B: Foil orientation, $\theta\left(^{\circ}\right)$ & 0 & 0 & 90 & 0 & 0 \\
C: Grain size, $d(\mu \mathrm{m})$ & 75 & 41.2 & 75 & 46.3 & 75 \\
& $($ level 2) & $($ level 2) & $($ level 2) & $($ level 1) & $($ level 2) \\
D: Punching frequency, $f(\mathrm{~Hz})$ & 0.2 & 0.2 & 0.2 & 0.2 & 0.25 \\
Springback $\left(^{\circ}\right)$ & 2.058 & 10.825 & 1.038 & 2.509 & 4.929 \\
\hline
\end{tabular}


Table 12 Experimental arrangements of contribution confirmation tests for negative springback.

\begin{tabular}{|c|c|c|c|c|c|}
\hline \multirow[t]{2}{*}{ Bending parameters } & \multicolumn{5}{|l|}{ Case } \\
\hline & (1) (Ref.) & $(2)$ & (3) & $(4)$ & (5) \\
\hline A: Foil thickness, $t(\mu \mathrm{m})$ & 75 & 100 & 75 & 75 & 75 \\
\hline B: Foil orientation, $\theta\left(^{\circ}\right)$ & 90 & 90 & 0 & 90 & 90 \\
\hline C: Grain size, $d(\mu \mathrm{m})$ & $\begin{array}{l}56.6 \\
\text { (level 1) }\end{array}$ & $\begin{array}{l}62.8 \\
\text { (level 1) }\end{array}$ & $\begin{array}{l}56.6 \\
\text { (level 1) }\end{array}$ & $\begin{array}{l}98.5 \\
\text { (level 2) }\end{array}$ & $\begin{array}{l}56.6 \\
\text { (level 1) }\end{array}$ \\
\hline D: Punching frequency, $f(\mathrm{~Hz})$ & 0.25 & 0.25 & 0.25 & 0.25 & 0.2 \\
\hline Negative springback $\left(^{\circ}\right)$ & -1.486 & -3.337 & -0.179 & -3.780 & -2.970 \\
\hline
\end{tabular}

In terms of springback (refer to Fig. 8), it was found that the springback amount in the case (2) experienced the biggest variation when compared with the reference case (1), indicating the foil thickness was the most influential parameter affecting the springback. The obtained result is in tandem with the result reported by Thipprakmas and Phanitwong [16]. To compare the influences of the foil orientation, grain size and punching frequency, the cases (3), (4) and (5) were compared with the case (1), respectively. The corresponding variations of the springback amount were $1.02^{\circ}, 0.451^{\circ}$ and $2.871^{\circ}$. Therefore, the punching frequency contributed more than the foil orientation. The grain size, nevertheless, was a minimal contributor to the springback.

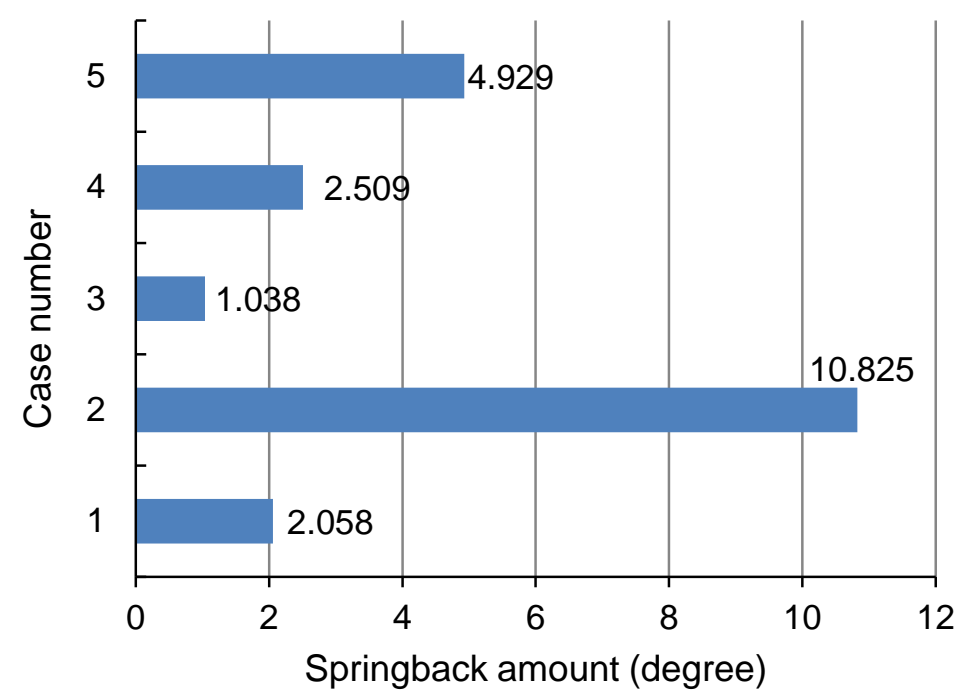

Fig. 8. Results of confirmation tests of the parameter contribution for springback. 
Similarly, the case (1) was also designated to be the reference case with respect to negative springback. As shown in Fig. 9, comparing the cases (2), (4) and (5) with the case (1), it was noteworthy that the grain size made the most contribution by increasing the negative springback amount of $2.294^{\circ}$ in the case (4), closely followed by the foil thickness giving rise to an increase of $1.851^{\circ}$ of the negative springback amount in the case (2). However, this is different from the results reported in the reference [16], which concluded that the bending angle was the dominant factor affecting the negative springback. Afterwards, the cases (3) and (5) were compared with the case (1), the variation of the negative springback amount in the case (5) was slightly larger $\left(1.484^{\circ}\right)$ than that in the case (3) $\left(1.307^{\circ}\right)$, revealing the punching frequency had more significant influence than the foil orientation.

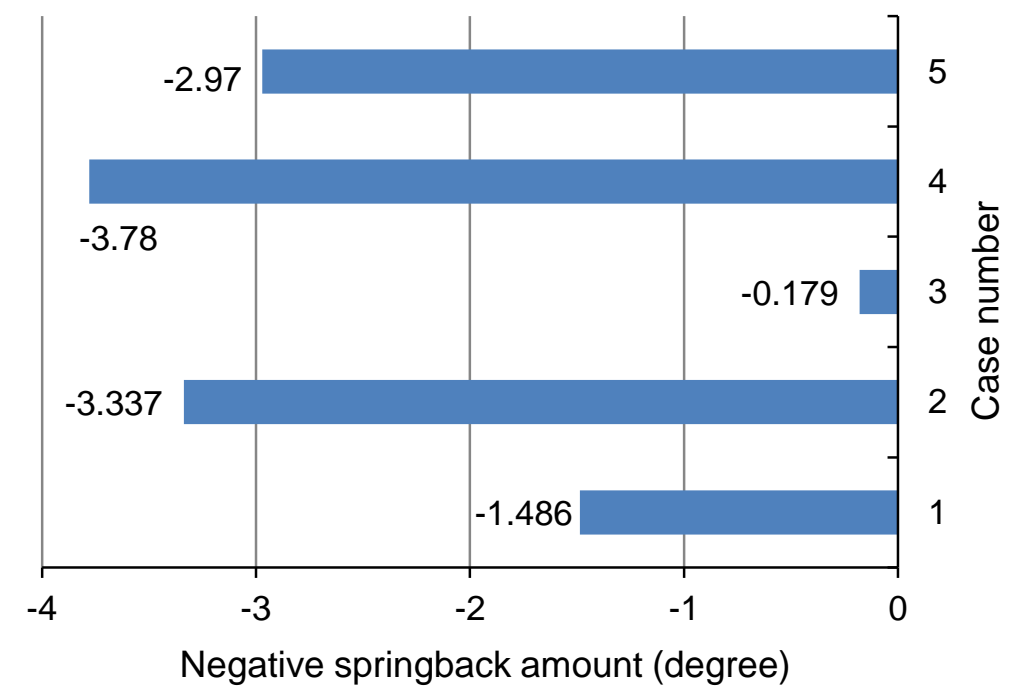

Fig. 9. Results of confirmation tests of the parameter contribution on negative springback.

Generally, the experimental results in the confirmation test have demonstrated the good accordance with the analysis results obtained in the study. Comparing the influences of all the four parameters, it is found that the foil orientation is a less-significant factor, showing little influence on both the springback and negative springback, which is possibly due to the decrease of its influence after the annealing treatment compared to that in the cold-rolled specimens. From this point of view, it is recommended to neglect this parameter in further studies of the micro W-bending process. Regarding the influence of the grain size, although it contributes the least to the springback, it is the dominant factor 
affecting the negative springback. Therefore, an in-depth investigation needs to be carried out in further studies to elaborate more on this issue.

\subsection{Mathematical models}

In this study, the output responses, namely the springback and negative springback angles, can be envisaged as a linear combination of the input parameters, i.e., foil thickness, foil orientation, grain size and punching frequency. Hence, a multiple-linear regression model using the least square method was employed to develop a mathematical model revealing the quantitative relationship between the parameters and corresponding response. The regression analysis was calculated using Minitab 17 based on the mean values of the springback and negative springback listed in Tables 3 and 4. Accordingly, the following regression equations for the springback and negative springback were obtained:

Springback angle $\left({ }^{\circ}\right)=11.16-0.3485 * t-0.0280 * \theta-0.0916 * d+70.2 * f$

Negative springback angle $\left({ }^{\circ}\right)=-2.31-0.02853 * t-0.00973 * \theta$

$$
-0.04325 * d+24.61 * f
$$

The performance of the obtained regression models was evaluated via ANOVA. Table 13 depicts the analysis results. It is indicated that the regression models for both the springback and negative springback are significant since P-value is below 0.05 with a confidence of $95 \%$. The standard errors of the models are reasonably small, approximate 2.2 and 0.3 for the springback and negative springback, respectively. Furthermore, the values of $\mathrm{R}$ square for the regression model of the springback and negative springback are $94.85 \%$ and $97.97 \%$ respectively, implying that the models are capable of explaining more than $94 \%$ of the variability of the springback and negative springback.

Table 13 Adequacy of regression models for springback and negative springback.

\begin{tabular}{lll}
\hline & $\begin{array}{l}\text { Regression model } \\
\text { for springback }\end{array}$ & $\begin{array}{l}\text { Regression model } \\
\text { for negative springback }\end{array}$ \\
\hline$P$-value & 0.028 (Significant) & 0.007 (Significant) \\
Standard error & 2.254 & 0.303
\end{tabular}




\begin{tabular}{lll} 
R square & $94.85 \%$ & $97.97 \%$ \\
Adjusted R square & $87.99 \%$ & $95.25 \%$ \\
\hline
\end{tabular}

Afterwards, the proposed models were used to predict the springback and negative springback at several observation points. The differences between the predicted angles and actual experimental results of the springback and negative springback are displayed in Figs. 10 and 11 respectively. It is demonstrated that the regression models for both the springback and negative springback are highly significant as the predicted values fit well with the experimental results.

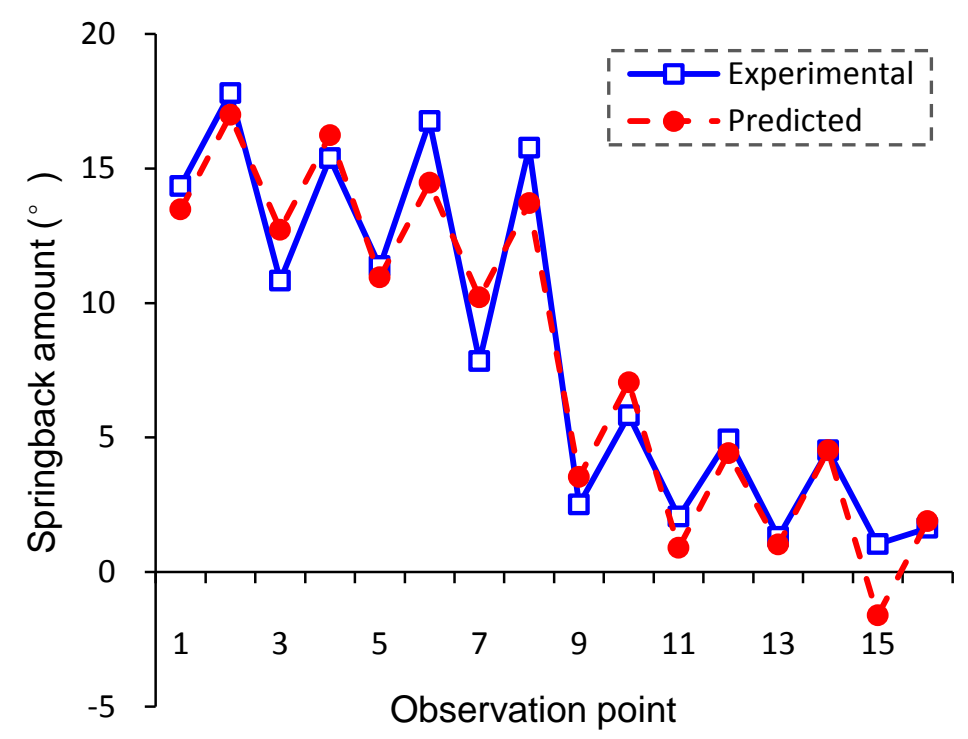

Fig. 10. Discrepancy between experimental and predicted results of springback.

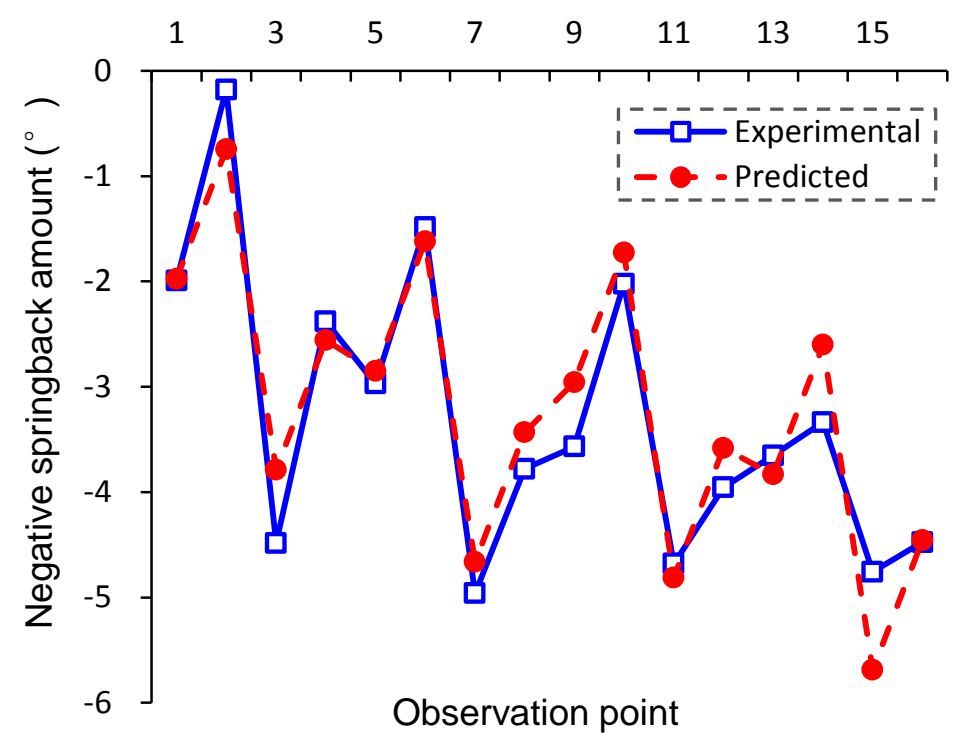

Fig. 11. Discrepancy between experimental and predicted results of negative springback. 


\section{Conclusions}

The study reported in this paper introduced a micro W-bending process for an investigation of influences of the parameters such as foil thickness, foil orientation, grain size and punching frequency, on the bending accuracy of the micro-bent parts. Micro W-bending experiments were conducted based on Taguchi $\mathrm{L}_{8} \mathrm{OA}$. S/N ratio, together with ANOVA, was utilized to investigate the optimal bending conditions and the extent of the contributions from the parameters on the springback and negative springback respectively. Confirmation tests have verified the results obtained. Mathematical models of the springback and negative springback were established and its adequacy was evaluated. Based on the results obtained, the following conclusions are drawn:

(1). The extent of the contributions to the sprinback from the four parameters investigated in the micro W-bending depends on on type of the springback: the springback and negative springback. The foil thickness contributed most (79.03\%) to the springback amount of the micro-bent parts, while the punching frequency contributed less (9.30\%). However, the foil orientation $(6.69 \%)$ and the grain size $(2.80 \%)$ exhibited minor contributions to the springback amount. In contrast, the negative springback amount was affected mostly by the grain size $(45.18 \%)$, closely followed by the foil thickness (24.31\%). The punching frequency also presented a significant contribution (19.08\%). The foil orientation, however, contributed least to the amount of the negative springback.

(2). Based on a analyses of the main influences of $\mathrm{S} / \mathrm{N}$ ratios and ANOVA, a optimum combination of the parameters for a low springback is A2B2C2D1, i.e., when foil thickness is $50 \mu \mathrm{m}$, foil orientation $90^{\circ}$, grain size $75 \mu \mathrm{m}$ and punching frequency $0.2 \mathrm{~Hz}$. Referring to the negative springback, the optimum bending condition is A1B1C1D2: foil thickness is $75 \mu \mathrm{m}$, foil orientation $0^{\circ}$, grain size $56.6 \mu \mathrm{m}$ and punching frequency 0.25 Hz.

(3). Significant improvements of the quality of the bent parts for the springback (decreased from $2.509^{\circ}$ to $1.038^{\circ}$ ) and the negative springback (decreased from $-3.568^{\circ}$ to $-0.179^{\circ}$ ) were observed in the confirmation tests. In addition, the percentage contribution of each parameter was also verified.

4. Good accordance between the predicted amounts of the springback and negative springback, using regression analysis and the experimental results, indicates that the 
established models are sufficiently accurate for the prediction of the bent angles of the micro parts in the micro W-bending.

\section{Acknowledgements}

The authors would like to acknowledge financial support from the Specialized Research Fund for the Doctoral Program of Higher Education of China (No. 20110181110084) and the sponsorship provided by the University of Strathclyde for conducting joint research in micro-forming with Sichuan University. The authors also would like to thank Mr. James Kelly for his assistance in the sample preparation for the measurement of grain size.

\section{References}

[1] M. Geiger, F. Vollertsen, R. Kals, Fundamentals on the manufacturing of sheet metal microparts, CIRP Annals - Manufacturing Technology, 45 (1996) 277-282.

[2] F. Vollertsen, Z. Hu, H.S. Niehoff, C. Theiler, State of the art in micro forming and investigations into micro deep drawing, Journal of Materials Processing Technology, $151(2004) 70-79$.

[3] J. Jeswiet, M. Geiger, U. Engel, M. Kleiner, M. Schikorra, J. Duflou, R. Neugebauer, P. Bariani, S. Bruschi, Metal forming progress since 2000, CIRP Journal of Manufacturing Science and Technology, 1 (2008) 2-17.

[4] Y. Qin, W.-N. W.A, J. Zhao, Forming of micro-sheet metal components, in: Y. Qin, Micromanufacturing Engineering and Technology (2nd edn), Elsevier, Oxford, 2015, pp. 299-322.

[5] S. Chikalthankar, G. Belurkar, V. Nandedkar, Factors affecting on springback in sheet metal bending: a review, International Journal of Engineering and Advanced Technology, 3 (2014) 247-251.

[6] B.L. Reddy, B.C. Rao, P.R. Reddy, P.R. Reddy, A review on springback in metal forming, International Journal of Engineering Research and Technology, 3 (2014) $646-655$.

[7] B. Chirita, Experimental study of the influence of blankholder force on spring-back of sheet metal, Archives of Civil and Mechanical Engineering, 3 (2003) 5-12. 
[8] Z. Tekıner, An experimental study on the examination of springback of sheet metals with several thicknesses and properties in bending dies, Journal of Materials Processing Technology, 145 (2004) 109-117.

[9] J.-T. Gau, C. Principe, M. Yu, Springback behavior of brass in micro sheet forming, Journal of Materials Processing Technology, 191 (2007) 7-10.

[10] Ö. Tekaslan, N. Gerger, U. Şeker, Determination of spring-back of stainless steel sheet metal in "V" bending dies, Materials \& Design, 29 (2008) 1043-1050.

[11] I.A. Choudhury, V. Ghomi, Springback reduction of aluminum sheet in V-bending dies, Proceedings of the Institution of Mechanical Engineers, Part B: Journal of Engineering Manufacture, 228 (2013) 917-926.

[12] M.K. Choi, H. Huh, Effect of punch speed on amount of springback in U-bending process of auto-body steel sheets, Procedia Engineering, 81 (2014) 963-968.

[13] M. Bakhshi-Jooybari, B. Rahmani, V. Daeezadeh, A. Gorji, The study of spring-back of CK67 steel sheet in V-die and U-die bending processes, Materials \& Design, 30 (2009) 2410-2419.

[14] R. Teimouri, H. Baseri, B. Rahmani, M. Bakhshi-Jooybari, Modeling and optimization of spring-back in bending process using multiple regression analysis and neural computation, International Journal of Material Forming, 7 (2014) 167-178.

[15] S. Thipprakmas, S. Rojananan, Investigation of spring-go phenomenon using finite element method, Materials \& Design, 29 (2008) 1526-1532.

[16] S. Thipprakmas, W. Phanitwong, Process parameter design of spring-back and spring-go in V-bending process using Taguchi technique, Materials \& Design, 32 (2011) 4430-4436.

[17] D. Hakan, Ö. Mustafa, S. Murat, Effects of material properties and punch tip radius on spring-forward in $90^{\circ} \mathrm{V}$ Bending processes, Journal of Iron and Steel Research, International, 20 (2013) 64-69.

[18] C.-C. Chen, Experimental Study on punch radius and grain size effects in V-bending process, Materials and Manufacturing Processes, 29 (2014) 461-465.

[19] C.J. Wang, X.W. Wang, B. Guo, D.B. Shan, Springback of C2680 brass foil in micro-bending test, Materials Science \& Technology, 17 (2009) 5-7.

[20] J.G. Liu, M.W. Fu, J. Lu, W.L. Chan, Influence of size effect on the springback of 
sheet metal foils in micro-bending, Computational Materials Science, 50 (2011) 2604-2614.

[21] A. Diehl, U. Engel, M. Geiger, Spring-back behaviour of thin metal foils in free bending processes, Multi-Material Micro Manufacture, (2005) 147-150.

[22] Y. Qin, Y. Ma, C. Harrison, A. Brockett, M. Zhou, J. Zhao, F. Law, A. Razali, R. Smith, J. Eguia, Development of a new machine system for the forming of micro-sheet-products, International Journal of Material Forming, 1 (2008) 475-478.

[23] S. Kalpakjian, R.S. Steven, Manufacturing Engineering and Technology, 5th ed., Prentice Hall, Singapore, 2005.

[24] W.H. Yang, Y. Tarng, Design optimization of cutting parameters for turning operations based on the Taguchi method, Journal of Materials Processing Technology, 84 (1998) $122-129$.

[25] B.H. Lee, J. Abdullah, Z.A. Khan, Optimization of rapid prototyping parameters for production of flexible ABS object, Journal of Materials Processing Technology, 169 (2005) 54-61.

[26] A.K. Sahoo, S. Pradhan, Modeling and optimization of Al/SiCp MMC machining using Taguchi approach, Measurement, 46 (2013) 3064-3072.

[27] S. Debnath, M.M. Reddy, Q.S. Yi, Influence of cutting fluid conditions and cutting parameters on surface roughness and tool wear in turning process using Taguchi method, Measurement, 78 (2016) 111-119.

[28] G. Taguchi, Y. Wu, Introduction to off-line quality control, Central Japan Quality Control Association, 1979.

[29] G. Taguchi, A.P. Organization, Introduction to quality engineering: designing quality into products and processes, Asian Productivity Organization, 1986.

[30] İ. Asiltürk, H. Akkuş, Determining the effect of cutting parameters on surface roughness in hard turning using the Taguchi method, Measurement, 44 (2011) 16971704.

[31] S.H. Park, J. Antony, Robust design for quality engineering and Six Sigma, World Scientific, 2008.

[32] H. Wielage, Z.Y. Hu, F. Vollertsen, Influence of punch velocity on spring back in micro forming, Key Engineering Materials, 504-506 (2012) 593-598. 
[33] S. Thipprakmas, Application of Taguchi technique to investigation of geometry and position of V-ring indenter in fine-blanking process, Materials \& Design, 31 (2010) 2496-2500. 